\title{
Biomass Expansion Factors Estimation of Chinese Fir (Cunninghamia Lanceolata) based on General Approach, Mixed Model Approach and Bayesian Hierarchical Approach
}

\author{
HUANG Xingzhao, WANG Zefu, XU Xiaoniu
}

School of Forestry \& Landscape of Architecture, Anhui Agricultural University, Hefei 230036, China

\begin{abstract}
BEF-stem volume equation has been widely applied to accurate stand biomass estimations. Stand biomass data were obtained from 53 permanent sample plots from Chinese fir plantations in Anhui and Fujian Province across China. There were significant differences between Fujian and Anhui from compared the stand biomass, volumes and BEF at difference age. The general approach, mixed model approach and Bayesian hierarchical approach were applied to establish BEF-stem volume equation for test effect factor of regions. Based on the fitting results, the mixed model approach and Bayesian hierarchical approach significant improving the accuracy of the stand biomass ( $p$-values < 0.001). But there was no significant between the mixed model approach and Bayesian hierarchical approach ( $\mathrm{p}$-value $=0.547$ ). The $\mathrm{R} 2$ values which used mixed model approach and Bayesian hierarchical approach were 0.159 and 0.161 higher than general approach. The RMSE and MAB values also declined 0.083 and 0.092, 0.143 and 0.148, respectively. Both the mixed model approach and Bayesian hierarchical approach were an effective method for estimating stand biomass at the regional scale.
\end{abstract}

Keywords: Chinese fir; BEF-stem volume equation; general approach; mixed model approach; Bayesian hierarchical approach.

\section{INTRODUCTION}

Chinese fir (Cunninghamia lanceolata) is an important native tree and a commercially valuable timber that is widely planted in the mountains of Southern China because of its straight shape and high resistance to bending and cracking. Chinese fir plantations comprise approximately 2.02 million ha, accounting for $1.72 \%$ of all timber plantations, with a volume of approximately 101 million $\mathrm{m}^{3}$, accounting for $0.28 \%$ of the total plantation volume (China Forestry Bureau 2014). China contains the largest area of Chinese fir plantations in the world.

Since forest ecosystems play irreplaceable roles in evaluating forest productivity regulating global carbon balance, stand biomass estimating and monitoring are becoming more important (Tomppo et al. 2010). Biomass expansion factors (BEF) converts stem volume directly to the dry weight of biomass component (Johnson \& Sharpe 1983, Karjalainen \& Kellomaki 1996). BEF value defines as W/V(W is the stand biomass and V is the stem volume) which correspond to age, site, and stand density classes in the forest (Brown \& Lugo 1984 1992, Schroeder et al. 1997, Fang et al. 199820012005 2007, Brown $\&$ Schroeder 1999, Nilsson et al. 2000). The stand biomass and stem volume data sets are typically collected from sample plots in the field. This technique is generally destructive, labour-intensive and time-consuming (Nafus et al. 2009). Established BEF equations can be applied to quantify and monitor the forest biomass, because the stem volume can be directly measured in the field.

Selecting the appropriate estimation equations is critical for accurate biomass estimations. Brown and her group (Brown \& Lugo 1992, Schroeder et al. 1997, Brown and Schroeder 1999, Brown et al.1999) and Fang and his group (Fang et al. 199619982001 2005) found that the BEF could be expressed as a consistent function of timber (stem) volume. However, further studies had indicated that this consistent function was not entirely suitable for different forest types. Fang and his colleagues (Fang et al. 1996199820012005 2007, Fang \& Wang 2001) have also derived a simple reciprocal equation to express the BEF-stem volume relationship. The BEF-stem volume equation improved the precision of biomass estimation for a specific forest type. Guo et al (2010) compared three equations to estimate the forest biomass and found $\mathrm{BEF}$-stem volume equation was better than others equations. These studies estimated BEFs parameters mainly using ordinary least-squares, which represent a 
HUANG Xingzhao et al. "Biomass Expansion Factors Estimation of Chinese Fir (Cunninghamia Lanceolata) based on General Approach, Mixed Model Approach and Bayesian Hierarchical Approach"

general approach. However, as raise the generality level of the estimations, forecast error in local area will increase. When the BEF-stem volume equation was built, how to make it has a wider range of applicability was a problem worthy of studying. Mixed model and Bayesian hierarchical model provides possible ways to solve this problem.

The mixed model approach is an improvement of the statistical approaches to estimate fixed effect parameters and random effects parameters, to improve the precision of prediction model, to eliminate the errors of different structure data, which can provide data variance, covariance and other information (Baayen et al 2008). Bayesian hierarchical approach can also incorporate variations during the model fitting process (Gilks et al. 1994, Carlin \& Louis 1996). When data are obtained from multiple regions or ages or site index, the Bayesian hierarchical approach assumes that subjects (regions, ages or site index) share common attributes. Bayesian hierarchical approach allows for the estimation of a very broad range of equations and can yield more realistic assessments of parameter estimate uncertainties. Compared to use mixed model approach and Bayesian hierarchical approach in effective and accurate for modeling trees biomass(Zhang \& Borders 2004, Fu et al. 2012, Mauricio et al. 2012, Zhang et al. 2013, Chen et al. 2016), there is a few studies that used these two approaches for accurate BEF-stem volume equation.

The objective of the study was to estimate BEF-stem volume equation of Chinese fir based on general approach, mixed model approach and Bayesian Hierarchical approach. In addition, the three approaches were compared with BEF estimation of Chinese fir.

\section{MATERIALS AND METHODS}

\section{Study Site}

The experimental sites in our study included two sites of Chinese fir plantation. One site was at Mazongling farm $\left(31.15^{\circ} \mathrm{N}, 115.40^{\circ} \mathrm{E}\right)$, Lu'an city, in Anhui Province, China. Mean annual precipitation is $1200 \mathrm{~mm}$. Mean annual temperature is $13.5^{\circ} \mathrm{C}$. The other site was at Dong'an farm $\left(26.50^{\circ} \mathrm{N}, 118.40^{\circ} \mathrm{E}\right)$, Jan'ou city, in Fujian Province, China. Mean annual precipitation is $1700 \mathrm{~mm}$. Mean annual temperature is $18.8^{\circ} \mathrm{C}$.

Three stands of 12 years, 23 years and 31 years Chinese fir were selected for the investigation in each site. Permanent sample plots of 26 and 27 plots were set in Mazongling farm and Dong'an farm, respectively. The tree diameter and height measurements in all of the plots were conducted after the tree height reached $1.3 \mathrm{~m}$ and each plot comprised an area of $20 \mathrm{~m} \times 30 \mathrm{~m}$. The trees were distributed in diameter classes of $8,10,12, \ldots, 42$. One or two trees in each diameter class were destructively sampled. A total 49 trees were sampled (28 trees in Mazongling farm and 29 trees in Dong'an farm). After the tree was felled, the fresh weights of stem wood, branch, foliage and root were measured, and the stem volume were calculated. All the subsamples were selected and weighed on a portable digital balance in the field. All subsamples were dried at $80^{\circ} \mathrm{C}$ and weighed again to determine the percentage of dry biomass for each part of the tree. The dry weight for each part was calculated as the fresh weight of that part multiplied by the corresponding percentage of dry biomass, while the total dry biomass for the tree was determined by combining the dry weights of different parts of the sampled tree. According to the diameter classes, stem volume and sample trees biomass, the stand volume and biomass of each plot were computed and showed in Tab. 1.

Tab.1. Descriptive statistics of plots sampled for fitting the BEF-stem volume equations (Std, standard deviation).

\begin{tabular}{|c|c|c|c|c|c|c|c|}
\hline \multirow[b]{2}{*}{ Site } & \multirow{2}{*}{$\begin{array}{l}\text { Attribute } \\
\mathrm{s}\end{array}$} & \multicolumn{2}{|l|}{12 years } & \multicolumn{2}{|l|}{23 years } & \multicolumn{2}{|l|}{31 years } \\
\hline & & $\begin{array}{l}\text { Biomass } \\
\text { (t/ha) }\end{array}$ & $\begin{array}{l}\text { Volume } \\
\left(\mathrm{m}^{3} / \mathrm{ha}\right)\end{array}$ & $\begin{array}{l}\text { Biomass } \\
(\mathrm{t} / \mathrm{ha})\end{array}$ & $\begin{array}{l}\text { Volume } \\
\left(\mathrm{m}^{3} / \mathrm{ha}\right)\end{array}$ & $\begin{array}{l}\text { Biomass } \\
(\mathrm{t} / \mathrm{ha})\end{array}$ & $\begin{array}{l}\text { Volume } \\
\left(\mathrm{m}^{3} / \mathrm{ha}\right)\end{array}$ \\
\hline \multirow{3}{*}{$\begin{array}{l}\text { Mazo } \\
\text { ngling }\end{array}$} & means & 44.47 & 35.63 & 122.30 & 87.71 & 208.41 & 127.07 \\
\hline & Std & 7.91 & 6.06 & 15.04 & 11.98 & 14.08 & 20.56 \\
\hline & $\begin{array}{l}\min - \\
\max \end{array}$ & $\begin{array}{l}33.96- \\
56.33 \\
\end{array}$ & $\begin{array}{l}28.52- \\
46.22 \\
\end{array}$ & $\begin{array}{l}101.38- \\
156.58\end{array}$ & $\begin{array}{l}70.01- \\
105.21 \\
\end{array}$ & $\begin{array}{l}191.99- \\
230.82\end{array}$ & $\begin{array}{l}106.04- \\
173.89\end{array}$ \\
\hline \multirow{3}{*}{$\begin{array}{l}\text { Dong } \\
\text { an }\end{array}$} & means & 52.11 & 47.74 & 155.19 & 108.84 & 244.92 & 169.83 \\
\hline & Std & 18.14 & 11.21 & 22.15 & 15.66 & 29.71 & 19.62 \\
\hline & $\begin{array}{l}\min - \\
\max \end{array}$ & $\begin{array}{l}23.42- \\
86.85\end{array}$ & $\begin{array}{l}31.12- \\
71.27\end{array}$ & $\begin{array}{l}113.72- \\
197.30\end{array}$ & $\begin{array}{l}85.13- \\
145.41\end{array}$ & $\begin{array}{l}210.38- \\
312.06\end{array}$ & $\begin{array}{l}149.31- \\
204.59\end{array}$ \\
\hline
\end{tabular}

$\mathrm{BEF}-$ stem volume equation 
HUANG Xingzhao et al. "Biomass Expansion Factors Estimation of Chinese Fir (Cunninghamia Lanceolata) based on General Approach, Mixed Model Approach and Bayesian Hierarchical Approach"

Forest biomass can be calculated by using BEF-stem volume equation. The BEF-stem volume relationship is a simple reciprocal equation, and defines as:

$$
B E F=a+\frac{b}{V}+e
$$

Where $\mathrm{BEF}$ is the sampled $\mathrm{BEF}$ and $\mathrm{V}$ is the sampled volume. $a$ and $b$ are the parameters. Error term $e$ assumes a normal distribution with a mean of zero and constant variance. Values for parameters are obtained by ordinary least squares in the general approach in this paper.

\section{Mixed Model Approach}

Nonlinear mixed-effects model offers a flexible tool for analyzing grouped data with models that depend nonlinearly upon their parameters. Nonlinear mixed-effects model is usually based on a mechanistic model of the relationship between the response and the covariates, their parameters can have fixed and random effects in their own right. Equation (1) can be altered by adding region random effects to the parameters $a$ and $b$. The nonlinear mixed-effects model corresponding to the equation (1) as:

$$
\begin{aligned}
& B E F_{j}=a_{j}+\frac{b_{j}}{V_{j}}+e_{j} \\
& {\left[\begin{array}{l}
a_{j} \\
b_{j}
\end{array}\right\rfloor=\left\lceil\beta_{a}\right\rceil\left[\begin{array}{cc}
\sigma_{a} & \sigma_{a} \sigma_{b} \\
\beta_{b}
\end{array}\right\rfloor+\left[\begin{array}{cc}
\sigma_{a} \sigma_{b} & \sigma_{b}
\end{array}\right\rfloor}
\end{aligned}
$$

Where $\mathrm{BEF}_{\mathrm{j}}$ and $\mathrm{V}_{\mathrm{j}}$ are the sampled $\mathrm{BEF}$ and $\mathrm{V}$ of the $\mathrm{j}^{\text {th }}$ region, respectively. $a i$ and $b i$ are the parameters, and each parameter contains fixed effects and random effects. $\beta_{a}$ and $\beta_{b}$ are the fixed effects which represents the population average of the individual parameters. $\sigma_{a}$ and $\sigma_{b}$ are the random effects which represents the deviations of the parameters from their population average. The random effects are assumed to be independent for different regions in this study. $e_{j}$ is the within-group errors which is assumed to be independent for different regions and to be independent of the random effects.

\section{Hierarchical Bayesian Approach}

Hierarchical Bayesian approach is based on combining data with prior information about parameter values to derive posterior probabilities of the various parameter values [27,28]. In our analysis, the distributional model $f(B E F \mid \theta)$ is for the biomass data $B E F=\left(B E F_{1}, \ldots, B E F_{j}\right)$, given a vector of parameters $\theta=\left(\theta_{1}, \ldots, \theta_{j}\right)$. Next is $\pi(\theta \mid \lambda)$, where $\lambda$ is a vector of hyper parameters [29]. The inference parameter $\theta$ is based on its posterior distribution:

$$
p(\theta \mid \mathrm{y}, \lambda)=\frac{p(\mathrm{y}, \theta \mid \lambda)}{\int p(\mathrm{y}, \theta \mid \lambda) d \theta}=\frac{\mathrm{f}(\mathrm{y} \mid \theta) \pi(\mathrm{y}, \theta \mid \lambda)}{\int \mathrm{f}(\mathrm{y} \mid \theta) \pi(\mathrm{y}, \theta \mid \lambda) d \theta}
$$

Parameters $a_{j}$ and $b_{j}$ have specific values for each region, allowing for polymorphic lines and multiple asymptotes. For the stand of $j^{\text {th }}$ region, the parameter $\theta_{j}$ in Equation (3) is defined as

$$
\theta_{j}=\left(a_{j}, b_{j}\right)=\left[\begin{array}{l}
a+a_{i} \\
b+b_{i}
\end{array}\right]
$$

The hierarchical Bayesian approach is used to fit Eq. 4 and is given by

$$
p(a, b \mid \text { data })=p(a, b) \prod_{j=1}^{J} \frac{\Gamma(a+b)}{\Gamma(a) \Gamma(b)} \frac{\Gamma\left(a+y_{j}\right) \Gamma\left(b+n_{j}-y_{j}\right)}{\Gamma\left(a+b+n_{j}\right)}
$$

where $n_{j}$ is the number of regions.

\section{Model Fitting}

General approach, mixed model approach and Bayesian hierarchical approach are used to fit the BEF-stem volume. Prediction determination coefficient $\left(R^{2}\right)$, root mean square error $(R M S E)$ and absolute bias $(M A B)$ are used to test fitting results. The statistics are given by the $R^{2}, R M S E$ and $M A B$ : 
HUANG Xingzhao et al. "Biomass Expansion Factors Estimation of Chinese Fir (Cunninghamia Lanceolata) based on General Approach, Mixed Model Approach and Bayesian Hierarchical Approach"

$$
\begin{aligned}
& R^{2}=1-\sum_{i=1}^{n}\left(y_{i}-y_{i}\right)^{2} / \sum_{i=1}^{n}\left(y_{i}-y^{\prime}\right)^{2} \\
& R M S E=\sqrt{\frac{\sum_{i=1}^{n}\left(\mathrm{y}_{i}-y_{i}\right)^{2}}{n-1}} \\
& M A B=\frac{\sum_{i=1}^{n}\left|y_{i}-y_{i}\right|}{n}
\end{aligned}
$$

$y_{i}$ is the observed biomass values, $y^{\prime}$ is arithmetic mean of all observed biomass values, $y_{i}$ is estimated biomass values, $\mathrm{n}$ is sample number.

Using the general approach as a base method, we use the nonlinear extra sum of squares method and the Lakkis-Jones test to assess whether mixed model approach and hierarchical Bayesian approach significantly improved the accuracy of the BEF-volumes equation(Bates \& Watts 1988, Barrio-Anta et al. 2006). We also assess the difference between mixed model approach and hierarchical Bayesian approach. The statistics are given by the nonlinear extra sum of squares and Lakkis-Jones test:

$$
\begin{aligned}
F & =\left(\frac{S S E_{B}-S S E_{N}}{d f_{B}-d f_{N}}\right) \frac{d f_{N}}{S S E_{N}} \\
L & =2 \operatorname{Ln}\left(\left(\frac{S S E_{B}}{S S E_{N}}\right)^{\frac{n}{2}}\right)
\end{aligned}
$$

where $\mathrm{SSE}_{\mathrm{B}}$ is the sum of squares of residuals in the general approach, $\mathrm{SSE}_{\mathrm{N}}$ is the sum of squares of residuals in the mixed model approach or the hierarchical Bayesian approach, $d f_{B}$ and $d f_{N}$ are the degrees of freedom of the general and he mixed model or the hierarchical Bayesian approaches, respectively, and $n$ is the number of observations used in the model fitting. The $F$-statistic follows an $F$-distribution and the $L$-statistic follows a $x^{2}$-distribution with v $=d f_{B}-d f_{N}$ degrees of freedom.

BEF-stem volume equation was fitted with mixed model approaches used NLME package and with the hierarchical Bayesian approach used in the MCMCglmm package (Hadfield 2010) and R2WinBUGS package (Sturtz et al. 2005) in R version 3.1.1 (R Development Core Team 2014).

\section{RESULTS}

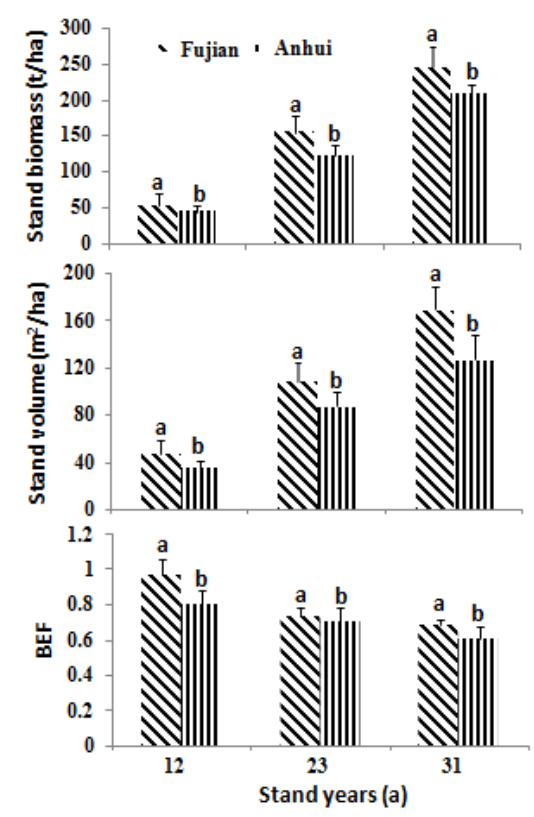

Fig.1. Compared the stand biomass, volumes and BEF at difference aegions. 
HUANG Xingzhao et al. "Biomass Expansion Factors Estimation of Chinese Fir (Cunninghamia Lanceolata) based on General Approach, Mixed Model Approach and Bayesian Hierarchical Approach"

The results showed that stand biomass, volumes and BEF vary considerably with age (Fig. 1). Both stand biomass and volumes increased with age. However, The BEF decreased with age because the annual growth rate of stand volumes was higher than stand biomass. From 12-year to 32-year the annual growth rate of stand biomass and volumes were 5.3\% and 6.3\%, respectively. But the annual growth rate of BEF was $-5.2 \%$. The fig 1 also showed that the stand biomass, volumes and BEF were significant differences between Fujian and Anhui. The Fig. 1 was shown that regions may play an important role when fitting the BEF-stem volume equation.

The general approach, mixed model approach and Bayesian hierarchical approach were used to fit the BEF-stem volume equation of Chinese fir from two regions (provinces)in China. The fitted result was shown in Tab. 2. The parameters of each approach were statistically significant $(p<0.001)$. Posterior probability distribution was an important index for validation the fitting process in Bayesian hierarchical approach. The posterior probability distribution of BEF-stem volume equations was shown in Fig. 2, which were normal distribution for each parameter. The parameters contained fixed effect parameters of $\beta_{a}$ and $\beta_{b}$ and random effect parameters of $\sigma_{a}$ and $\sigma_{b}$ in the mixed model approach. The parameters of $a_{1}$ and $b_{1}$ are the parameters of Fujian, $a_{2}$ and $b_{2}$ are the parameters of Anhui in Bayesian hierarchical approach. The parameters which fitted mixed model approach and Bayesian hierarchical approach could predict the BEF in different regions.

Tab.2.BEF-stem volume equation fitted results of the general approach, mixed model approach and Bayesian hierarchical approach. (1, 2 and 3 represent general approach, mixed model approach and Bayesian hierarchical approach, respectively. $a_{1}$ and $b_{1}$ are the parameters of Fujian, $a_{2}$ and $b_{2}$ are the parameters of Anhui.)

\begin{tabular}{|l|l|l|l|l|l|}
\hline Fitted approach & Parameter & Estimate values & Std & T-value & P-value \\
\hline 1 & $a$ & 0.600 & 0.019 & 30.634 & $<0.001$ \\
\hline & $b$ & 12.927 & 1.336 & 9.673 & $<0.001$ \\
\hline \multirow{5}{*}{2} & $\beta_{a}$ & 0.605 & 0.015 & 40.663 & $<0.001$ \\
\hline & $\beta_{b}$ & 12.651 & 2.977 & 4.251 & $<0.001$ \\
\hline & $\sigma_{a}$ & 0.0001 & & & \\
\cline { 2 - 6 } & $\sigma_{b}$ & 3.883 & & & \\
\cline { 2 - 6 } & $\sigma_{a b}$ & -0.268 & & & \\
\cline { 2 - 6 } & $e$ & 0.062 & & & \\
\hline \multirow{5}{*}{3} & $a_{1}$ & 0.601 & 0.014 & 41.253 & $<0.001$ \\
\cline { 2 - 6 } & $b_{1}$ & 16.739 & 2.241 & 7.662 & $<0.001$ \\
\cline { 2 - 6 } & $a_{2}$ & 0.764 & 0.016 & 40.977 & $<0.001$ \\
\cline { 2 - 6 } & $b_{2}$ & 2.040 & 0.397 & 7.254 & $<0.001$ \\
\hline
\end{tabular}
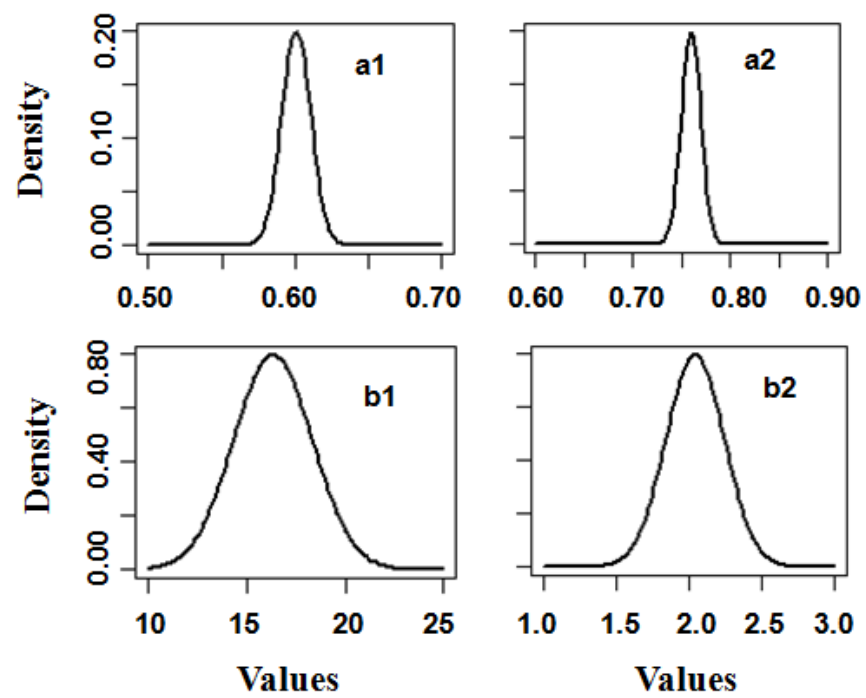

Fig.2. Posterior probability densities of parameters for BEF-stem volume equation. ( $a_{1}$ and $b_{1}$ are the parameters of Fujian, $a_{2}$ and $b_{2}$ are the parameters of Anhui.)

The $R^{2}, R M S E$ and $M A B$ of the BEF-stem volume equation estimated by the general approach, mixed model approach and Bayesian hierarchical approach were shown in Table 3 . The $R^{2}$ values which used mixed model approach and Bayesian hierarchical approach were 0.159 and 0.161 higher than general 
HUANG Xingzhao et al. "Biomass Expansion Factors Estimation of Chinese Fir (Cunninghamia Lanceolata) based on General Approach, Mixed Model Approach and Bayesian Hierarchical Approach"

approach. Thus, the RMSE and $M A B$ values also declined 0.083 and $0.092,0.143$ and 0.148 , respectively. For test the difference between the three approaches, the nonlinear extra sum of squares (F-value) and the Lakkis-Jones (L-value) were used to inter-comparison. There was significant between general approach and mixed approach (p-value $<0.001$ ). And between general approach and Bayesian hierarchical approach also too. We detected that the mixed model approach and Bayesian hierarchical approach increased the goodness-of-fit statistics. But there was no significant between the mixed model approach and Bayesian hierarchical approach ( $\mathrm{p}$-value $=0.547$ ).

Tab.3. Compare the general approach, mixed model approach and Bayesian hierarchical approach. (1, 2 and 3 represent general approach, mixed model approach and Bayesian hierarchical approach, respectively.)

\begin{tabular}{|l|l|l|l|l|l|l|l|}
\hline Approach & $R^{2}$ & $R M S E$ & $M A B$ & $F$ values & $\operatorname{Pr}>|F|$ & $L$ values & $\operatorname{Pr}>|L|$ \\
\hline 1 & 0.643 & 0.301 & 0.376 & & & & \\
\hline 2 & 0.802 & 0.214 & 0.233 & & & & \\
\hline 3 & 0.804 & 0.209 & 0.228 & & & & \\
\hline 1 vs 2 & & & & 16.437 & $<0.001$ & 423.157 & $<0.001$ \\
\hline 1 vs 3 & & & & 16.509 & $<0.001$ & 431.245 & $<0.001$ \\
\hline 2 vs 3 & & & & 1.049 & 0.547 & 18.254 & 0.547 \\
\hline
\end{tabular}

The performance of the three approaches was shown in Fig. 3. Boxplots illustrated the residual tendency of BEF for the general approach, mixed model approach and Bayesian hierarchical approach in each region. Both the mixed model approach and Bayesian hierarchical approach residuals were closer to both the zero-line and the observed values compared to those of the general approach. Thus, both the mixed model approach and Bayesian hierarchical approach yielded more accurate parameter estimates.

1

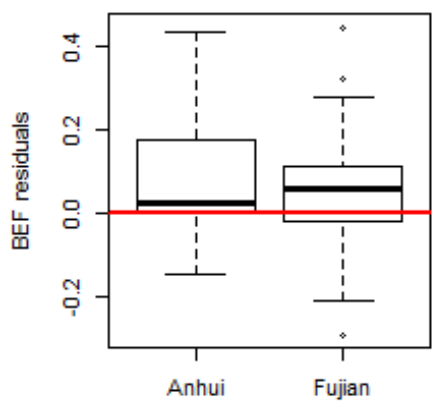

2

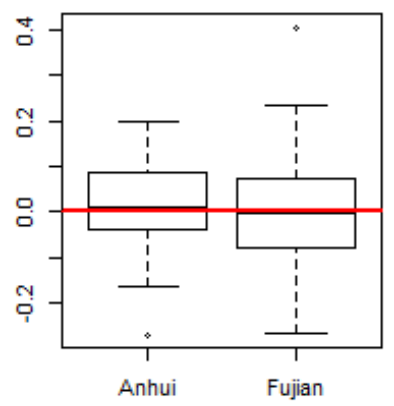

3

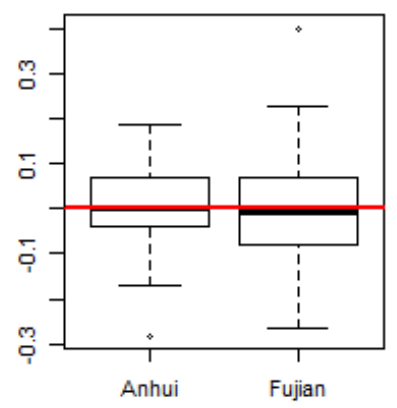

Fig.3. Residual boxplots comparing the general approach, mixed model approach and Bayesian hierarchical approach. (1, 2 and 3 represent general approach, mixed model approach and Bayesian hierarchical approach, respectively.)

\section{DISCUSSION}

The total biomass stock of Chinese fir increased continuously during the last three decades, which was one of the most important tree species for the biomass carbon pool in China (China Forestry Bureau 2014). The accurate estimation of stand biomass is critical for accounting and monitoring Chinese fir carbon stock. In this study, the BEF data was collected from difference regions of Fujian and Anhui Province. It encompasses large variations in climatic, soil physical and chemical properties that affect stand biomass and volumes accumulation. From compared the stand biomass, volumes and BEF at difference age, we found there were significant differences between Fujian and Anhui. This result indicated we must to consider regional difference when fitted the BEF-stem volume equation.

In early studies, they focused how developed the equations to biomass estimation and which equations could improve the precision of biomass estimation for a specific forest type (Brown \& Lugo 1992, Schroeder et al. 1997, Brown and Schroeder 1999, Brown et al.1999, Fang et al. 1996 1998). And Fang et al(1996 199820012005 2007)found the BEF-stem volume equation was better way to estimate the stand biomass. But there was no study to compare the fitting approaches when used the BEF-stem volume equation. The BEF-stem volume equation was fitted in our study which used the general approach, mixed model approach and Bayesian hierarchical approach, respectively. Used the 
HUANG Xingzhao et al. "Biomass Expansion Factors Estimation of Chinese Fir (Cunninghamia Lanceolata) based on General Approach, Mixed Model Approach and Bayesian Hierarchical Approach"

F-value and L-value to test the three approaches, we detected that the mixed model approach and Bayesian hierarchical approach significant increased the goodness-of-fit statistics. The $R^{2}$ values which used mixed model approach and Bayesian hierarchical approach were 0.159 and 0.161 higher than general approach. The RMSE and $M A B$ values also declined 0.083 and $0.092,0.143$ and 0.148 , respectively. The mixed model approach and Bayesian hierarchical approach were better methods to improve the precision of biomass estimation at difference regional scales.

The emphasis of this study is mainly on methodology. Some studies only compared the general approach and mixed model approach (Wang et al. 2008, Fu et al.2012), or general approach and Bayesian approach (Zhang et al. 2013), or Bayesian approach and Bayesian hierarchical approach (Chen et al. 2016) for estimation accuracy of tree biomass. We comprehensive compared the general approach, mixed model approach and Bayesian hierarchical approach for estimation accuracy of stand biomass. The general approach is assumed the parameters were fixed and unknown constant, whereas mixed model approach and Bayesian hierarchical approach assumed the parameters change with geographical factors (Anholt et al.2000, Li et al. 2012). When we used regions as a geographical factor, the parameters of each region were obtained which fitted the mixed model approach and Bayesian hierarchical approach. Thus, the precision of biomass estimation was improved in BEF-stem volume equation.

The mixed model approach and Bayesian hierarchical approach provide effective methods to develop BEF-stem volume equation at different scales, and they could be applied to construct other equation(Fang \& Bailey 2001, Daniel \& Michael. 2004, Case \& Hall 2008). The mixed model approach and Bayesian hierarchical approach which is more appropriate should be required to confirm in further study. There was no significant between the mixed model approach and Bayesian hierarchical approach in our result. Both the mixed model approach and Bayesian hierarchical approach performed to predict the stand biomass which only consider region as effect factor. When increase the effect factor (such as stand species, altitude et al), the mixed model approach may be more appropriate. In Bayesian approaches, how to define prior information of the parameters is firstly step. We usually assume that the parameters follow some statistical distribution. However, we must use the posterior probability distribution to calibrate the prior information(Ellison 2004, Carlin et al 2006, Wagner \& Tüchler 2010). The fitting process of Bayesian hierarchical approach will be more complicated with the effect factor increase. Generally speaking, the mixed model may be more flexible and applicable. But this inference should be calibrated which approach is the effective method between the mixed model approach and Bayesian hierarchical approach.

In addition to regional stand biomass and carbon stock assessments, our results indicate the mixed model approach and Bayesian hierarchical approach can be used in analysis of the carbon dynamics of forest ecosystems in difference regions. The BEF-stem volume equations presented in this study are applicable for difference regions where stand species were the same. Stand-level estimates of biomass according the BEF-stem volume equation are needed to consider the species effect in a region. Both the effects of regional scales and stand species was consider. It is important to be able to improve precision of biomass estimation and observe the dynamics of carbon stocks in different regions and stand species.

\section{CONCLUSIONS}

The stand biomass data of Chinese fir were collected from different regions of Anhui and Fujian Province, which encompass climatic, soil physical and chemical properties that affect stand biomass and volumes accumulation. From compared the stand biomass, volumes and BEF at difference age, we found there were significant differences between Fujian and Anhui. This result indicated variabilities to the BEF-stem volume equation, suggesting that the fitting approaches are better consider regional difference. In this paper, we applied the general approach, mixed model approach and Bayesian hierarchical approach to establish BEF-stem volume equation. Based on the fitting results, we detected that the mixed model approach and Bayesian hierarchical approach significant improving the accuracy of the stand biomass ( $p$-values $<0.001$ ). The $R^{2}$ values which used mixed model approach and Bayesian hierarchical approach were 0.159 and 0.161 higher than general approach. The RMSE and MAB values also declined 0.083 and $0.092,0.143$ and 0.148 , respectively. We also compared the mixed model approach and Bayesian hierarchical approach. There was no significant between these two approaches. Both the mixed model approach and Bayesian hierarchical approach were an effective method for estimating stand biomass at the regional scale. 
HUANG Xingzhao et al. "Biomass Expansion Factors Estimation of Chinese Fir (Cunninghamia Lanceolata) based on General Approach, Mixed Model Approach and Bayesian Hierarchical Approach"

\section{ACKNOWLEDGEMENTS}

This research was supported by the National Natural Science Foundation of China (NSFC, No. 31370626 and 31070588), The National Key Research and Development Program of China (2016YFD0600304-03).

\section{REFERENCES}

[1] Anholt BR, Werner E, Skelly DK (2000). Effect of food and predators on the activity of four larval ranid frogs. Ecology 81:3509-3521.

[2] Baayen RH, Davidson DJ, Bates DM (2008). Mixed-effects modeling with crossed random effects for subjects and items. Journal of Memory and Language 59: 390-412.

[3] Bates DM. Watts DG (1998). Nonlinear Regression Analysis and Its Applications; John Wiley \& Sons: New York, NY, USA, p. 102.

[4] Barrio-Anta M, Balboa-Murias M Castedo-Dorado F, Diéguez-Aranda U Alvarez-González JG (2006). An ecoregional model for estimating volume, biomass and carbon pools in maritime pine (Pinuspinaster Ait) stands in Galicia (northwestern Spain). Forest Ecology and Management 223: 24-34.

[5] Brown S, Lugo AE (1984). Biomass of tropical forests: a new estimate based on forest volumes. Science 223: 1290-1293.

[6] Brown S, Lugo AE (1992). Aboveground biomass estimates for tropical moist forests of Brazilian Amazon. Interciencia 17: 8-18.

[7] Brown SL, Schroeder PE (1999). Spatial patterns of aboveground production and mortality of woody biomass for eastern U.S. forests. Ecological Application 9: 968-980.

[8] Brown SL, Schroeder PE, Kern JS (1999). Spatial distribution of biomass in forests of the eastern USA. Forest Ecology and Management 123, 81-90.

[9] Case B, Hall RJ(2008).Assessing prediction errors of generalized tree biomass and volume equations for the boreal forest region of west-central Canada. Canadian Journal of Forest Research 38: 878-889.

[10] Carlin BP, Clark JS, Gelfand AE (2006). Hierarchical Modelling for the Environmental Sciences: Statistical Methods and Applications; Oxford University Press: Oxford, UK, p. 103.

[11] Chen DS, Huang XZ, Sun XM, Ma W, Zhang SG (2016). A Comparison of Hierarchical and Non-Hierarchical Bayesian Approaches for Fitting Allometric Larch (Larix.spp.) Biomass Equations. Forests 7: doi:10.3390/

[12] China Forestry Bureau (2014). The Eighth Forest Resource Survey Report. Chinese Forestry Press: Beijing, China, p. 14.

[13] Cowles MK, Carlin BP (1996). Markov chain Monte Carlo convergence diagnostics: A comparative review. Journal of the American Statistical Association 91: 883-904.

[14] Daniel BH, Michael C(2004). Multivariate Multilevel Nonlinear Mixed Effects Models for Timber Yield Predictions. Biometrics 60(1): 16-24.

[15] Ellison AM(2004). Bayesian inference in ecology. Ecology Letters 7(6):509-520.

[16] Fang JY, Liu GH, Xu SL (1996). Biomass and net production of forest vegetation in China. Acta Ecologica Sinica 16: 497-508 (in Chinese).

[17] Fang JY, Wang GG, Liu GH, Xu SL (1998). Forest biomass of China: an estimation based on the biomass-volume relationship. Ecological Application 8: 1084-1091.

[18] Fang JY, Chen AP, Peng CH, Zhao SQ, Ci LJ (2001). Changes in forest biomass carbon storage in China between 1949 and 1998. Science 292: 2320-2322.

[19] Fang JY, Oikawa T, Kato T, Mo W,Wang ZH (2005). Biomass carbon accumulation by Japan's forests from 1947-1995. Global Biogeochem. Cycles 19, GB2004, doi:10.1029/2004GB002253.

[20] Fang JY, Guo ZD, Piao SL, Chen AP (2007). Terrestrial vegetation carbon sinks in China, 1981-2000. Sci. China Ser. D 50 (9): 1341-1350.

[21] Fang JY, Wang ZM (2001). Forest biomass estimation at regional and global levels, with special reference to China's forest biomass. Ecological Research 16: 587-592. 
HUANG Xingzhao et al. "Biomass Expansion Factors Estimation of Chinese Fir (Cunninghamia Lanceolata) based on General Approach, Mixed Model Approach and Bayesian Hierarchical Approach"

[22] Fang Z, Bailey RL (2001). Nonlinear Mixed Effects Modeling for Slash Pine Dominant Height Growth Following Intensive Silvicultural Treatments. Forest Science 47(3): 287-300.

[23] Fu LY, Zeng WS, Tang SZ, Sharma RP, Li HK (2012).Using linear mixed model and dummy variable model approaches to construct compatible single tree biomass equations at different scales - A case study for Masson pine in Southern China. Journal of Forest Science 58(3): 101-115.

[24] Gilks WR, Thomas A, Spiegelhalter DJ (1994). A language and program for complex Bayesian modelling. Statistician 43: 169-178.

[25] Guo ZD, Fang JY, Pan YD, Birdsey R (2010). Inventory-based estimates of forest biomass carbon stocks in China: A comparison of three methods. Forest Ecology and Management 259:1225-1231.

[26] Hadfield JD (2010). MCMC methods for multi-response generalized linear mixed models: The MCMCglmm R package. Journal of Statistical Software 33: 1-22.

[27] Johnson WC, Sharpe DM (1983). The ratio of total to merchantable forest biomass and its application to the global carbon budget. Canadian Journal of Forest Research 13: 372-383.

[28] Karjalainen T, Kelloma"ki S (1996). Greenhouse gas inventory for land use changes and forestry in Finland based on international guidelines. Mitigation Adapt. Strategies Global Climate 1: 51-71.

[29] Li R, Stewart B, Weiskittel A(2012). A bayesian approach for modelling nonlinear longitudinal/hierarchical data with random effects in forestry. Forestry 85:17-25.

[30] Mauricio ZC, Carlos AS, Lauren A (2012). Probability distribution of allometric coefficients and Bayesian estimation of aboveground tree biomass. Forest Ecology and Management 277: 173-179.

[31] Nafus AM, McClaran MP, Archer SR, Throop HL (2009). Multispecies allometric models predict grass biomass in semidesert rangeland. Rangeland Ecology and Management 62: 68-72.

[32] Nilsson S, Shvidenko A, Stolbovoi V, Gluck M, Jonas M, Obersteiner M (2000). Full carbon account for Russia. Interim report, IR-00-021. International Institute for Applied Systems Analysis, Laxenburg, Austria.

[33] Schroeder P, Brown S, Mo J, Birdsey R, Cieszewski C (1997). Biomass estimation for temperate broadleaf forests of the United States using inventory data. Forest Science 43: 424-434.

[34] Sturtz S, Ligges U, Gelman A (2005). R2WinBUGS: A package for running WinBUGS from R. Journal of Statistical Software 12: 1-16.

[35] Tomppo E, Gschwantner T, Lawrence M, McRoberts RE (2010). National Forest Inventories: Pathways for Common Reporting. 1st Ed. New York, Springer: 610.

[36] Wagner H, Tüchler R (2010). Bayesian estimation of random effects models for multivariate responses of mixed data. Computational Statistics and Data Analysis 54: 1206-1218.

[37] Wang M, Borders BE, Zhao D(2008).An empirical comparison of two subject-specific approaches to dominant heights modeling, the dummy variable method and the mixed model method. Forest Ecology and Management 255:2659-2669.

[38] Zhang YJ, Borders BE (2004). Using a system mixedeffects modeling method to estimate tree compartment biomass for intensively managed loblolly pines- an allometric approach. Forest Ecology and Management 194: 145-157.

[39] Zhang XQ, Duan AG, Zhang JG (2013). Tree biomass estimation of Chinese fir (Cunninghamialanceolata) based on Bayesian method. PLoS ONE 8(11), e79868. 